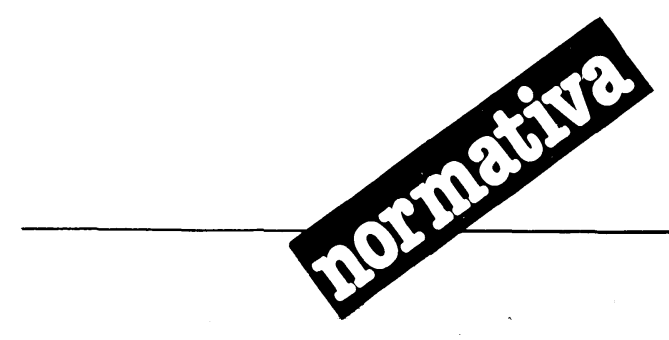

\title{
NORMATIVA RELACIONADA CON LAS CONSTRUCCIONES DE TIERRA
}

\author{
Maria Jesús Guinea (V.M.B.C.)
}

\section{PREPARACION DE LA MUESTRA DE BARRO}

- Se eliminan los granos del esqueleto mineralógico de tamaño superior a $2 \mathrm{~mm}$, por selección o tamizado, previamente secado y triturado.

- Con la vista se comprueba la finura del grano medio más grande de $2 \mathrm{~mm}$, asi como su porcentaje en volumen.

- El barro liberado de las inclusiones de grano superiores a $2 \mathrm{~mm}$, se aplasta con un martillo de albañil $(2,5 \mathrm{~cm} . \times 2,5$ $\mathrm{cm}$. cabeza) sobre una chapa metálica, añadiendo escasamente agua, hasta conseguir una pasta coherente.

- La pasta conseguida se levanta con un cuchillo y se la corta en tiras.

- Se entremezclan las tiras y se machaca otra vez con el martillo la pasta conseguida, se vuelve a cortar y a machacar de nuevo.

- Se repite este procedimiento hasta que se note textura regular en la parte en contacto con la chapa.

- En el caso de que el barro esté seco al comenzar la preparación, deberá reposar 6 horas después de machacado, cubierto con un trapo húmedo. Si es barro de naturaleza arcillosda durante 12 horas. Al reposar el barro la humedad se repartirá igualmente en toda su masa.

NORMA DIN 18952. Hoja 2

\section{PLASTICIDAD NORMALIZADA}

- 200 gramos de barro preparado se densifican golpeando varias veces en una chapa.

- A continuación se forma una bola con la mano durante un tiempo limitado, para que su superficie no elimine una gran cantidad de agua y la plasticidad se mantenga uniforme en la masa.

- Se deja caer sobre una chapa rigida desde una altura de $2,00 \mathrm{~m}$. medida al centro de la bola.
- Se considera que el barro tiene una plasticidad normalizada, si la depresión originada en la esfera es de un diámetro de $50 \mathrm{~mm}$.

- En el caso de que la depresión no sea circular, la diferencia entre el eje máximo y minimo de ésta, no deberá ser mayor de $2 \mathrm{~mm}$.

NORMA DIN 18952. Hoja 2.

\section{ENSAYO DE RETRACCION}

- Con una muestra de barro de plasticidad normalizada, se rellena el molde de la probetas cúbicas de $70 \mathrm{~mm}$ con barro de plasticidad normalizada.

- En el plano superior de la probeta se marca, mediante un cuchillo y un patrón, la distancia de $20 \mathrm{~cm}$. y la línea que define la distancia.

- La probeta deberá reposar sobre una superficie de cristal engrasada con aceite, durante tres dias, a una temperatura no superior a $20^{\circ} \mathrm{C}$.

- Transcurrido este tiempo puede complementarse el secado, mediante horno a $60 \circ \mathrm{C}$, hasta que se aprecie cambio en la longitud.

- El valor de la retracción seca, se determina por la media de los dos ensayos, que no deberán diferenciarse en más de $2 \mathrm{~mm}$

NORMA DIN 18952. Hoja 2.

\section{RESISTENCIA A LA COMPRESION}

- Para la comprobación de la resistencia a compresión, se fabrican por lo menos 4 probetas cúbicas de $70 \mathrm{~m} / \mathrm{m}$. con barro de plasticidad normalizada.

- Se retira inmediatamente el encofrado y la muestra se seca a $200 \mathrm{C}$ en un lugar sin aire corriente y con sombra, sobre una parrilla.
- Después del 5.0 dia puede acelerarse el proceso de secado, hasta una temperatura máxima de $80^{\circ} \mathrm{C}$.

- En cuanto se compruebe en cubos fabricados complementariamente, que el núcleo está seco, se alisan las superficies paralelas expuestas a la compresión.

- La compresión se realiza en la dirección de llenado y el valor de la resistencia a compresión será el valor medio de tres ensayos en el valor de la sección calculable de $30 \mathrm{~cm}^{3}$.

NORMA DIN 18952. Hoja 2.

\section{CLASIFICACION DE SUELOS}

\section{ASTM D 3282-73}

Standard Recommended Practice for classification of soils and voil - aggregale Mixturer for Highway construction purposes.

\section{ASTM D 2487-69}

Standard Test Method for classification of soils for engincesing purposes.

\section{ASTM D 2488-69}

Standard Recommended Practice for Description of soils (Visual - Manual - Procedure).

\section{ASTM D 422-63}

Standard Method for Particle - size analysis of soils.

\section{ASTM D 1140-54}

Standard Test Method for Amount of Material in soils finer thun the No. $200(75 \mathrm{~mm}$.) siere.

\section{ASTM D 421-58}

Standard Method for Diy preparation of soil sampler for particle size analysis and determination of soil constants. 
RELACION DE NORMAS: INFORMACION RELATIVA A NORMAS RELACIONADAS CON LA TIERRA COMO MATERIAL DE CONSTRUCCION,

Preparada por el Equipo

V.M.B.C.

- Determinación de «Finos». NORMA UNE -7.135 .

- Preparación de la «Pasta Normalizada». DIN. 18.952 - Hoja 2

- Determinación de la "Humedad" mediante secado en estufa. MNE. 7.328.75.

- «Preparación de muestra" para los ensayos de suelos. UNE. 7.327.75

- Granulometría "Cedazos y Tamices". UNE. 7.050

- Determinación del «Limite Liquido» por el método de la cuchara. UNE. 7.377.75.
- Determinación del "Limite Plástico" de un suelo. UNE. 7.378.75.

- Determinación del "Peso especifico" de un terreno. UNE. 7001

- Determinación de la "Porosidad" de un terreno. UNE. 7045.

- Determinación del "Limite de retracción" de un terreno. UNE. 7016.

- Ensayo de apisonado de suelos por el metodo «Proctor modificado". UNE. 7.365.79

- Determinación del contenido de "Materia orgánica" en los suelos. MNE. 7.368.77.

- Reconocimiento de "Sulfatos" solubles en los suelos. UNE. 7.369.75

- Contenido de "Sulfatos" solubles en los suelos. MNE. 7.370.75

- "Toma de muestras superficiales" de suelo de tipo inalterado. MNE. 7.371.75.

- «Relación entre los tamices» de la serie
UNE. 7050 y los de varias series extranjeras. MNE. 7177.

- "Granulometria» de suelos por tamizado. NLT - 104/72.

- Densidad «in situ» por el método de la arena. NLT - 109/72.

- «Equivalente de arena». NLT - 113/72.

- "Carbonatos" en los suelos por el método del calcimetro de Bernard. NLT $-116 / 72$

- "Material que pasa el tamiz 0,080 UNE" en los áridos. NLT - 152/72.

- "Densidad relativa y absorción de áridos finos". NLT - 154/76.

- "Densidad minima de una arena». NLT 204/72.

- «Densidad máxima y humedad óptima de las mezclas de suelo-cemento, mediante apisonado con masa». NLT - 301/72.

- "Congelación - deshielo de probetas de suelo - cemento". NLT - 303/72.

\section{publicación del I.E.T.C.C.}

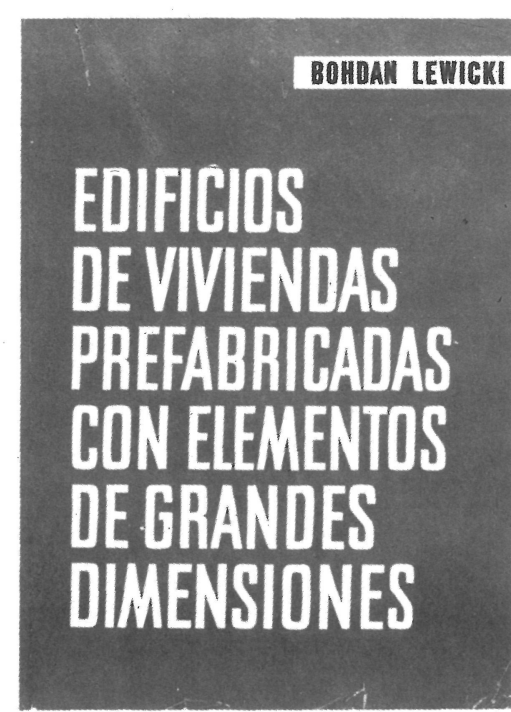

\section{Bohdan Lewick}

Este libro trata de los problemas relativos a la construcción de los edificios de viviendas - publicos realizados con elementos prefabricados de grandes dimensiones. Se han estudiado los problemas de arriostramiento asi como los que plantea la resistencia de los elementos y de la estructura; se han examinado las cuestiones de orden higrotermico, acústico y de resistencia al fuego; también se ha profundizado en el estudio de la estanquidad de los muros exteriores y de las juntas.

La obra incluye numerosas ilustraciones que dan detalles de diversas soluciones, as como ejemplos de cálculo, tablas de valores numéricos, diagramas y ábacos.

Un volt en encuadernado en tela, de $24 \times 17 \mathrm{~cm}$, compuesto de 616 págs.

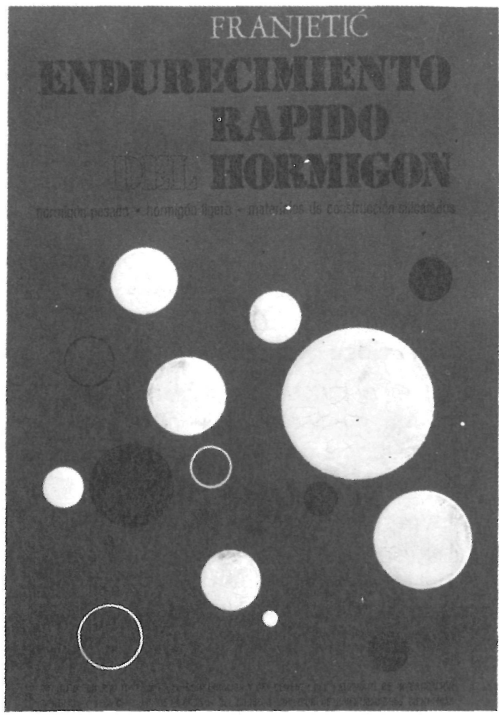

Zorislav Franjetić

En la obra de Franjetic se expone de una forma minuciosa, ordenada y sistemática, todo un cuerpo de doctrina que reúne el conocimiento actual sobre el endurecimiento rápido del hormigón. Parte el autor de los rápido del hormigón. Parte el autor de los
principios básicos y llega a las últimas conprincipios básicos y llega a las últimas con-
secuencias y realidades técnicas y econó micas.

Es una obra de consulta, tanto para el in vestigador sobre la materia como para el proyectista y el realizador y montador de plantas e instalaciones y equipos de curado y endurecimiento rápido.

Un volumen encuadernado en cartóné, de $17 \times 24,5 \mathrm{~cm}$, compuesto de 385 págs. 110 figuras y 10 tablas.

Precios: 2.500 ptas.; \$USA 36.00

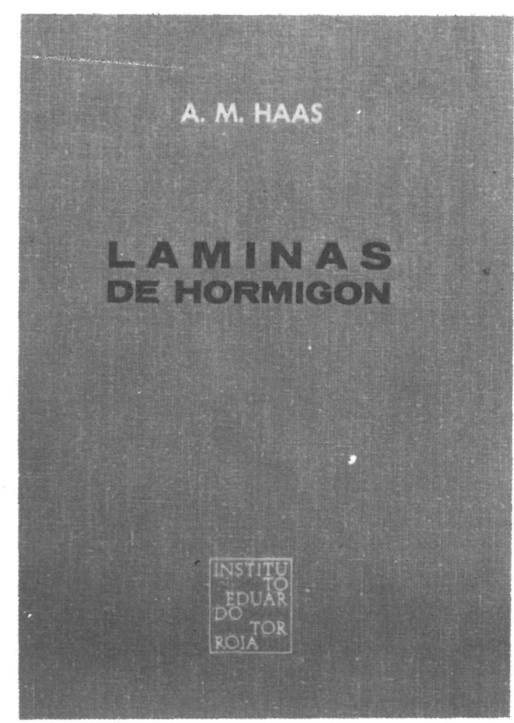

\section{A. M. Haas}

Al escribir este libro el autor intentó poner a disposición de los estudiantes y de los ingenieros unos conocimientos prácticos, adecuados para servir de guía en el diseño y construcción de láminas delgadas de hormigón.

El autor está convencido de que él éxito en el diseño de una lámina exige, por parte del proyectista, un examen de las tres fases por las que pasa la materialización de la lámina: el diseño, el análisis estructural y la construcción de la estructura.

Un volumen encuadernado en tela, de $17 \times 24,5 \mathrm{~cm}$, compuesto de 420 págs. 141 figuras, 22 fotografias y 6 tablas.

Precios: 2.500 ptas.; \$USA 36.00

Precios: 2.500 ptas.; \$USA 36.00 